Article

\title{
Application of GIS-Based Multi-Criteria Decision Technique in Exploration of Suitable Site Options for Anaerobic Digestion of Food and Biodegradable Waste in Oita City, Japan
}

\begin{abstract}
Micky A. Babalola
Graduate School of Education, Hiroshima University,1-1-1 Kagamiyama, Higashi-Hiroshima, Hiroshima 739-8524, Japan; mickba15@hiroshima-u.ac.jp or mickyamune2@gmail.com; Tel.: +81-82-424-4393

Received: 30 May 2018; Accepted: 2 July 2018; Published: 4 July 2018

Abstract: Recently, the popularity of anaerobic digestion (AD) has been increasing, and selecting a site for $\mathrm{AD}$ is a complex process for both individuals and decision-makers. This process requires the selected site to fulfill all regulation requirements, simultaneously reducing environmental, sociocultural, technical, political, economic, and public health costs. A geographic-information-system-based multi-criteria decision analysis (GIS-MCDA) is presented in this study to evaluate and examine the suitability of the study area in order to propose a suitable site for an AD facility in Oita City, Japan. Multi-criteria evaluation (MCE) was used to standardize the map layers into fuzzy membership functions. The proximity variables were classified into seven factors and three constraint groups, specifically, environmental, sociocultural, and technical/economic criteria. The proximity and criteria maps were combined using weighted linear combination (WLC) techniques, and the resulting suitability map was evaluated on a grading scale of $0-255 \mathrm{~B}$. The analytical hierarchy process (AHP) ranking analysis indicated that an area of about $13.36 \mathrm{~km}^{2}$ from the entire study area is the most suitable and that the remaining two options are still suitable for the intended purpose, but the entire decision will be entrusted to the decision-makers' judgment.
\end{abstract}

Keywords: GIS; multi-criteria decision analysis; anaerobic digestion; food and biodegradable waste; site selection

\section{Introduction}

The increased quantities of municipal solid waste (MSW) generated in developed countries have created questionable issues of concern and importance. Food scraps and biodegradable waste remain the most significant part of the waste stream, and it barely seems possible that the throwing away or disposal of such waste will present any significant challenges. As such, many factors and unseen circumstances make this a complex issue of great importance even for a developed country such as Japan [1,2].

The generation of such waste is more than the municipal government and local authorities can handle. They are left to struggle with the cost of waste management, a large sum of food and biodegradable waste (FBW), methods of treatment, regulations, and the impact on the local environment [3]. A further complication in the food and biodegradable waste management (FBWM) problem is the difficulties in finding the right treatment or disposal facilities and locations for these facilities, inappropriate treatment methods (unlawful dumping), clashes involving different areas over the long-distance transportation of waste, and the concern of waste treatment amenities [3-6].

It appears that the confirmed material recycling and the ecological advantages of anaerobic digestion (AD) over landfill, composting, and incineration have made it a more attractive waste 
treatment method for FBW [7,8]. The International Solid Waste Association (ISWA) [9] and Babalola [7] concluded that the introduction of AD into the MSW stream can support local authorities and decision-makers who wish to effectively manage FBW. Khoo et al. [10] also pointed out that implementing the AD recycling process will significantly reduce the impact of global warming potential. Franchetti [11] similarly supports this by illustrating with a case study in which AD systems are preferred over landfills in terms of cost, energy, and greenhouse emissions. Regardless of the demanding efforts in other techniques of FBW treatment, $\mathrm{AD}$ as a waste treatment option is seen in many countries as the most promising, stable, and reliable approach for MSW management [12].

The development of FBWM systems using AD technology touches upon the selection of treatment, recycling, and disposal facilities; the collection of FBW from the source of generation; the choices of the type and route of transport; site selection; and the means of by-product distribution. Among these challenging issues, Kemal Korucu \& Erdagi [13] mentioned that the most problematic aspect of MSW disposal process is the selection of a site for any chosen waste treatment facility.

A new site (location) for an AD plant is not an exception, as it involves complicated activities that require a thorough decision-making procedure. The complexity of these decisions is due to multi-criteria and objectives, which rely on environmental, sociocultural, technological, economic, and public health issues, as well as the active trait of MSW insecurity [6,14-16]. As shown by Khan \& Faisal [17], MSW decision-making often involves nonspecific challenging issues, and, correspondingly, humans are limited to some extent in dealing with these issues without any analytical aids. Additionally, Tavares et al. [6] mentioned that different types of MSW treatment facilities have their own specifications, which are, in various ways, case-sensitive, and these should be taken into consideration when making decisions on the basis of criteria (goals, objectives, and sub-objectives). Therefore, it is expected that sociocultural ideas on local knowledge, the economic feasibility, the technical skills, and the environmental information in the development of comprehensive, clear, and systematic measures be taken into consideration. In this context, the geographic-information-systems-based multi-criteria decision analysis (GIS-MCDA) was proposed to decrease insecurities and give decision-makers the ability to make reliable judgments.

GIS-MCDA has been acknowledged in playing an essential and leading role in the siting of MSW disposal facilities [6,15,18-21]. GIS-MCDA is a procedure that transforms and integrates mapping criteria or factors (geographic data) and decision-makers' preferences to reach a final value judgment of the decision alternatives [18,22,23]. According to Gbanie et al. [14], GIS-MCDA remains a robust system that fine-tunes as well as uses non-spatial and spatial data to generate helpful information in order to make significant decisions. As spatial decision issues, in general, require a comprehensive set of realistic multiple alternatives, conflicting goals, and evaluation criteria, therefore, GIS-MCDA helps to reduce the communication gaps between stakeholders and decision-makers by providing a sound and acceptable assessment based on a logical, transparent, and documented procedure $[18,19,23,24]$.

Several GIS-MCDA techniques have been widely used for evaluating and identifying suitable and potential locations for siting MSW treatment facilities [6,14,15,19-21,23-32]. These techniques include the analytic network process (ANP), the analytic hierarchical process (AHP), Boolean overlay, fuzzy logic, ordered weighted averaging (OWA), and weighted linear combination (WLC). Kemal Korucu \& Erdagi [13] and Malczewski [19] provide a comprehensive criticism and literature survey on GIS-MCDA. In their studies, they first examine and outline the approaches developed for creating maps using GIS tools and then classify them according to areas of application for the siting of MSW treatment facilities.

A substantial number of these works, such as those mentioned above, are based upon the evaluation of a suitable location for landfill facilities using hydrogeological, morphological, and geological properties. Tavares et al. [6], Chang et al. [33], and Chiueh et al. [34] combined GIS and the AHP to evaluate the allocation of funding and conduct an environmental impact assessment of a MSW incineration plant. Most of these works on the suitable site selection mentioned in the 
literature are mainly for MSW landfills and incineration plants; no studies have yet applied WLC-GIS to determine a potentially suitable location for an $\mathrm{AD}$ plant.

Although WLC is a structured approach, it uses an offset aggregation rule in which the decision set includes the final value judgement of the alternatives and favorable criteria outweigh unfavorable criteria anywhere $[19,29]$. WLC is flexible enough to allow full tradeoff amidst criteria and the use of the AHP in the extraction of criteria weight [29].

In this paper, WLC was used to develop a framework based on GIS-MCDA to evaluate potentially suitable locations for siting an AD waste treatment facility in Oita City, Japan. The framework uses the WLC module in IDRISI software (Taiga edition) to evaluate, characterize, and assess the potentially suitable site using the constrained maps and standardized factor maps (fuzzy set membership function of 0-255 B). Cluster analysis (CA) is also used to group the results towards obtaining the most suitable site options. Spatial autocorrelation by Moran's index (I) is utilized to analyze and measure spatial correlation in the suitability map layer. Another aim of this paper is to illustrate the flexibility of applying this approach (WLC) by examining different decision alternatives for AD plant siting. The proposed framework developed in this study will not only complement the present waste management system, but will support and recommend the development of a comprehensive, integrated solid waste management plan in the future and for the long term.

\section{Materials and Methods}

The waste treatment siting process in a landscape requires the consideration of complex criteria and evaluation steps in order to find a proper site and at the same time eradicate the overall negative impacts and consequent effects on the local environment. The described case study is intended to demonstrate the application, flexibility, and robustness of the GIS-based MCDA methodology regarding siting waste treatment facilities. The study area and modeling approach are discussed in the following section.

\subsection{Study Area}

Oita City covers a total area of $502.39 \mathrm{~km}^{2}$, extending from $33^{\circ} 04^{\prime} 11^{\prime \prime} \mathrm{N}$ to $33^{\circ} 17^{\prime} 24^{\prime \prime} \mathrm{N}$ and from $131^{\circ} 57^{\prime} 46^{\prime \prime}$ E to $131^{\circ} 25^{\prime} 07^{\prime \prime}$ E. Oita is the capital city of Oita Prefecture and has an estimated population of 479,466 inhabitants (as of 30 January 2018) with 218,532 households and a density of 954.35 inhabitants $/ \mathrm{km}^{2}[35,36]$. The city is bounded to the northwest by Beppu City, to the west by Yufu City, to the southwest by Taketa City, to the south by Bungo-ōno City, and to the southeast by Usuki City; Beppu Bay and the Seto Inland Sea are to the north. It has a comprehensible uniqueness between the land cover types, which are mainly rice fields, farm land, forests, waste land, urban areas, road networks, rivers, water bodies, and the sea (Figure 1). Oita City is one of the nation's leading industrial areas; it spreads over the coastline overlooking the Seto Inland Sea, and nearly $65 \%$ of the population is constituted by middle-income families, while $10 \%$ represents low-income families $[35,36]$.

The recent developments in Japan have been towards promoting the utilization of biomass resources (e.g., food, kitchen waste, rice strolls, wood, etc.) to achieve a sustainable biomass circulation society and to increase the food independence ratio. Since June 2000, the Japanese Government has introduced different national policies that place a high emphasis on the recovery of carbon-rich and biodegradable waste through material recycling [2,37]. Among these national policies is the promotion of the utilization of a recyclable food waste act known as the Food Recycling Law; the Sound Material-Cycle Society in the act references the Biomass Nippon Strategy [1,2,37]. Most prefectures in Japan have adopted this strategy, including Oita Prefecture, with its own Oita zero-waste strategy [38]. For this purpose, the proposed framework on AD plant siting could contribute to a large extent to the support of the above strategy, which could also, in turn, reduce the burden of waste management in the prefecture. Consequently, this could also be seen as an opportunity to look at new options for FBW 
disposal and as a possibility to address issues associated with FBW efficiently, eventually also being applied to the surrounding cities.

The amount of waste generated and the population of Oita City were among the reasons for this city being chosen for this study. Currently, a total of 21,976 $\mathrm{t}$ of food and kitchen waste is generated per month, and a closer look at the circumstances of the FBW generation in Oita City shows that the MSW generated contains a reasonable fraction (about 38.6\%) of FBW [36]. FBW and other burnable waste types are sent straight to incineration, which is mostly handled by two incineration plants. As such, it is meaningful to evaluate the study area for the suitability of intruding AD waste treatment.

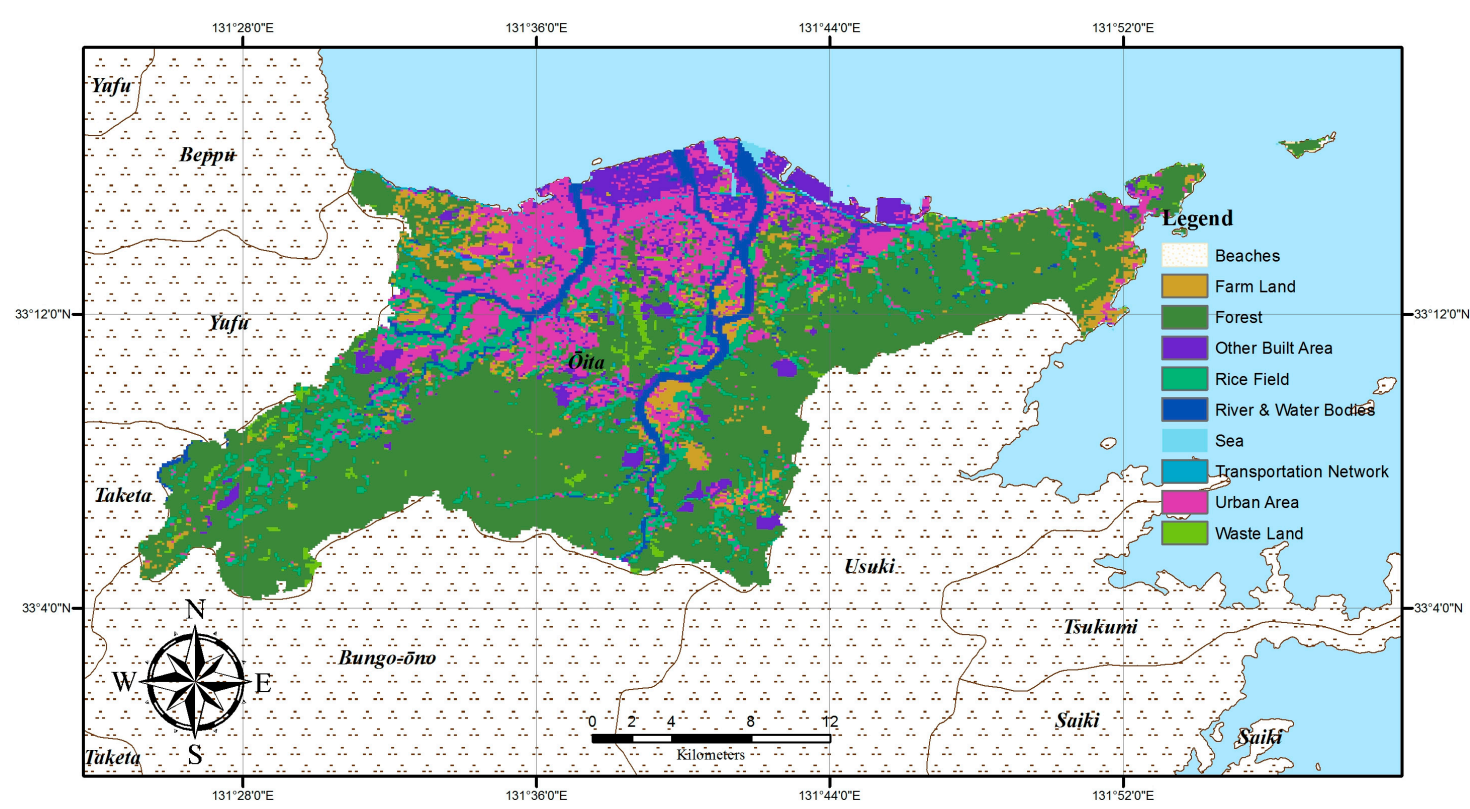

Figure 1. Land-use map of Oita City.

\subsection{Criteria Evaluation: Constraints and Factors}

The land-use map was evaluated using a land-cover map, an administration boundary map, road and river data, and a digital elevation model (DEM). The land-cover map and land-use map were produced by utilizing land-use tertiary mesh data from the National Land Numerical Information of Japan (NLNI), which was created using TERRA (Aster) and ALOS at a scale of 1:50,000 [39]. Unsupervised classification using a cluster classifier (IDRISI Taiga software) was performed to categorize the images into 10 land-cover classes (with an overall accuracy of 55.5\%), as shown in Figure 1, namely, rice fields, farm land forests, waste land, urban areas, transportation networks, other built areas, rivers and water bodies, and beaches and the sea. The administration boundary, river, and road maps were created from NLNI data at a scale of 1:50,000, while the DEM data was downloaded from ASTER-DEM with $30 \mathrm{~m}$ resolution [40].

Waste-treatment-facility site-selection processes are complex and complicated, as different criteria and judgments are required. The conceptual model and the flowchart of the methodology are shown in Figure 2, and Table 1 shows the description of the criteria (constraints and factors) used in this study, which was obtained from an analysis of the Waste Management and Public Cleansing Law (WMPCL) document and related literature [3,6,13,15,19,20,26,29,41-43]. From these, three constraints (main criteria) and seven factors (sub-criteria) that were significant in the siting of the waste treatment plant (AD) were identified. The three constraints were environmental, sociocultural, and technological/economic constraints, and the seven factors were water bodies, roads, powerlines, residential areas, forestry, tourist attraction areas, and slope gradients (briefly described in Table 1). 


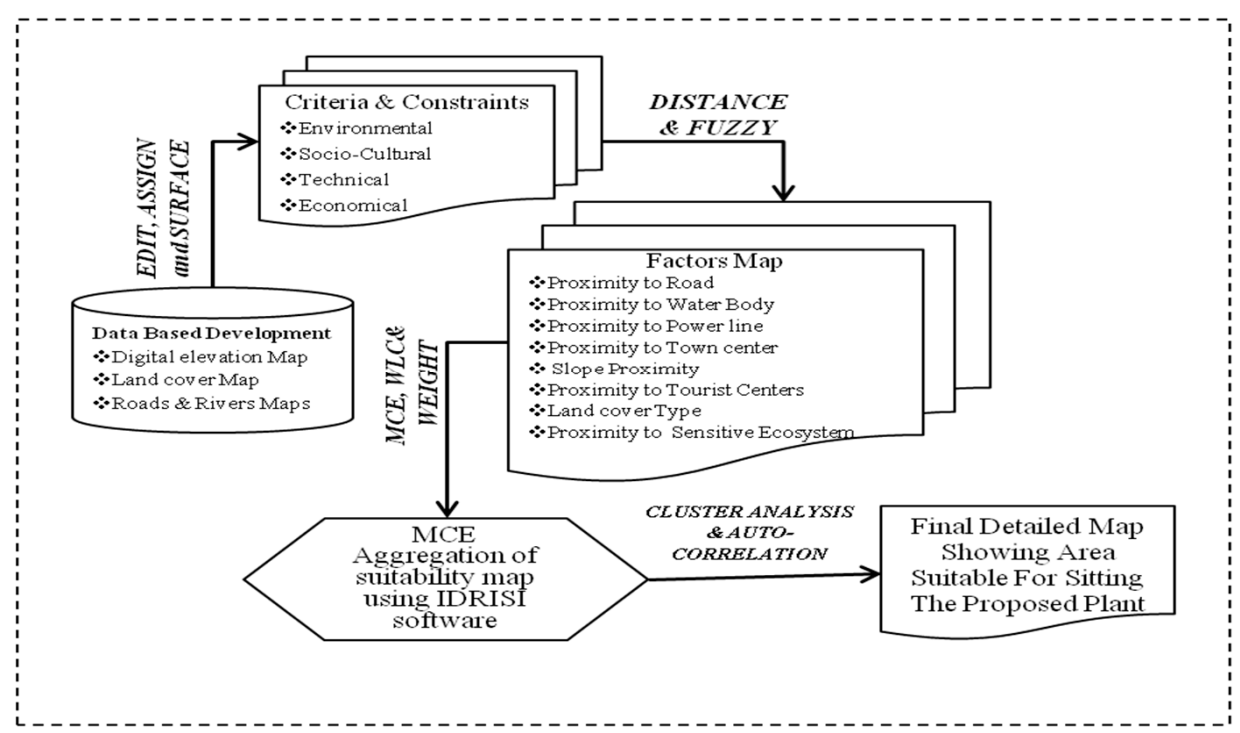

Figure 2. Conceptual geographic information system (GIS) model for anaerobic-digestion waste disposal site selection.

Table 1. Constraints and factors used in the development of database.

\begin{tabular}{|c|c|c|}
\hline Constraint & Factors & Description \\
\hline \multirow{2}{*}{ Environmental } & Water bodies & $\begin{array}{l}\text { Safe distance from any stream, wetland, lake, pool, river, or water } \\
\text { source to prevent pollution }\end{array}$ \\
\hline & Forests & $\begin{array}{l}\text { Distance from forests must be reasonable enough to protect forests, } \\
\text { farms, and gardens }\end{array}$ \\
\hline \multirow{2}{*}{ Sociocultural } & Residential areas & $\begin{array}{l}\text { Safe minimum distance to avoid Not in My Backyard (NIMBY) } \\
\text { phenomenon and reasonable distance for waste transportation }\end{array}$ \\
\hline & $\begin{array}{l}\text { Touristic and } \\
\text { cultural centers }\end{array}$ & $\begin{array}{l}\text { Safe distance with legal protection for any national parks, lakes, } \\
\text { and pools; tourist centers; and protected and cultural areas }\end{array}$ \\
\hline \multirow{3}{*}{ Technical/economic } & Roads & Safe distance from any passages, roads, or highways \\
\hline & Slope gradients & Steep land is not always required for most waste disposal facilities \\
\hline & Powerlines & $\begin{array}{l}\text { Distance from any powerlines is very essential as the electricity } \\
\text { produced will need to be sold to nearby residential areas }\end{array}$ \\
\hline
\end{tabular}

\subsection{Weighted Linear Combination}

GIS-based MCDA is a way of combining and processing spatial data into useful decisions, and it is most commonly accomplished by one of the three techniques: Boolean overlay, WCL, or OWA $[24,30,44]$. Boolean overlay is the process whereby all criteria (constraints and factors) are standardized to Boolean values ( 0 and 1 ) and are then combined using one or more logical operators (intersection and union). For instance, the logical operator AND (intersection) denotes the lowest risk, whereas the OR (union) operator denotes the highest risk in the decision-making. WCL is the process whereby continuous factors (criteria) are standardized to an ordinary numeric range and are thereafter aggregated through the method of weighted averaging [24,44]. The result (continuous suitability map) is then created with one or more Boolean constraints to match qualitative criteria (factors) and the final threshold to obtain the decisive result [24,30,44]. Additionally, WLC methods allow criteria to trade off their qualities and offer much more flexibility than the Boolean overlay technique [24]. OWA is a technique similar to WLC but that takes into consideration two sets of weights. The first set of weights controls the relative importance of a specific factor/criterion, whereas the second set of weights controls the order of the combination of the weighted criteria (i.e., the control of the overall 
level of tradeoff between factors and of the level of risk) [18,19,24]. Acceding to Eastman [24], OWA gives a complete spectrum of degree of tradeoff involved and degree of risk in the solution, while the WLC technique represents an average risk in decision-making, where there is the potential for a full tradeoff. In WLC, weight is given to each factor, followed by adding the result to yield a suitability map that aggregates factors $[30,44]$ :

$$
S=\sum W i X i
$$

where $S$ represents suitability,

- Wi is the weight of each factor $i$,

- $\quad$ and $X i$ is the criterion score of factor $i$.

In situations in which Boolean constraints are used, the operation is adjusted by multiplying the factors of suitability estimated by the product of the constraints:

$$
S=\sum W i X i \times \prod C j
$$

where $C j$ is the criterion score of constraint $j$

- $\quad$ and $\Pi$ is the product.

For the scoring criterion, it is essential that the factors are standardized before combination, as more criteria are measured under different scales and if required will be transformed in a way in which all factor images are positively correlated with suitability. The approach for the standardization used in this study is linear scaling utilizing the minimum and maximum valves as scaling points [30,44]:

$$
X i=\frac{\left(R i-R_{\min }\right)}{\left(R_{\max }-R_{\min }\right)} \times \text { Standardized_Range, }
$$

where $R i$ is the raw score of factor $i$,

- $R_{\min }$ is the minimum score,

- $\quad$ and $R_{\max }$ is the maximum score.

The above technique is the procedure of converting the statement of set membership into values [44]. Eastman [24] pointed out that if continuous factors are recognized as a truly fuzzy set, then it is easy to recognize this as just one of many possible set membership functions. Eastman [24] also proposed the usage of either $0-255 \mathrm{~B}$ scales or a real-number $0-1$ scale for the standardization of factors as the range of fuzzy set membership functions (standardized range).

\subsection{Pairwise Comparison}

In the development of criterion weight, there are several methods available, among which this study uses the pairwise comparison method [24]. Pairwise comparison is recommended at this stage in order to extract the relevant weight $[15,18,20,24,30]$. The weight or judgment assigning process within the IDRISI Taiga software environment represents the same procedure as the AHP. For further information on how the AHP can be applied, see Saaty [45] and Saaty \& Vargas [46].

\section{Results}

The intended GIS-based MCDA model developed for the siting of an AD plant includes the assessment and integration of environmental, sociocultural, and technical/economic constraints. For this purpose, multi-criteria evaluation (MCE) was selected as the proper way to address the multi-criteria problem. It should be noted that all the calculations and analyses in this study were carried out using Clark Lab's IDRISI Taiga GIS software [24]. 


\subsection{Constraint Map}

The development of the waste disposal suitability map entails three constraints, namely, environmental, sociocultural, and technical/economic constraints. These constraints represent geographical areas that are prohibited and not considered suitable for AD plant site selection. They were developed using Boolean Expression [24].

\subsubsection{Environmental Constraint Map}

This map is derived from the land-cover map (as in Figure 1), by reclassifying those areas not acceptable for development as $0 \mathrm{~s}$ and those places in which development is acceptable as $1 \mathrm{~s}$. This results in a Boolean map (Figure 3). In this case, the only areas that are not available for development were water bodies and forested areas (reclassified as 0 ). Others (reclassified as 1) can be developed.

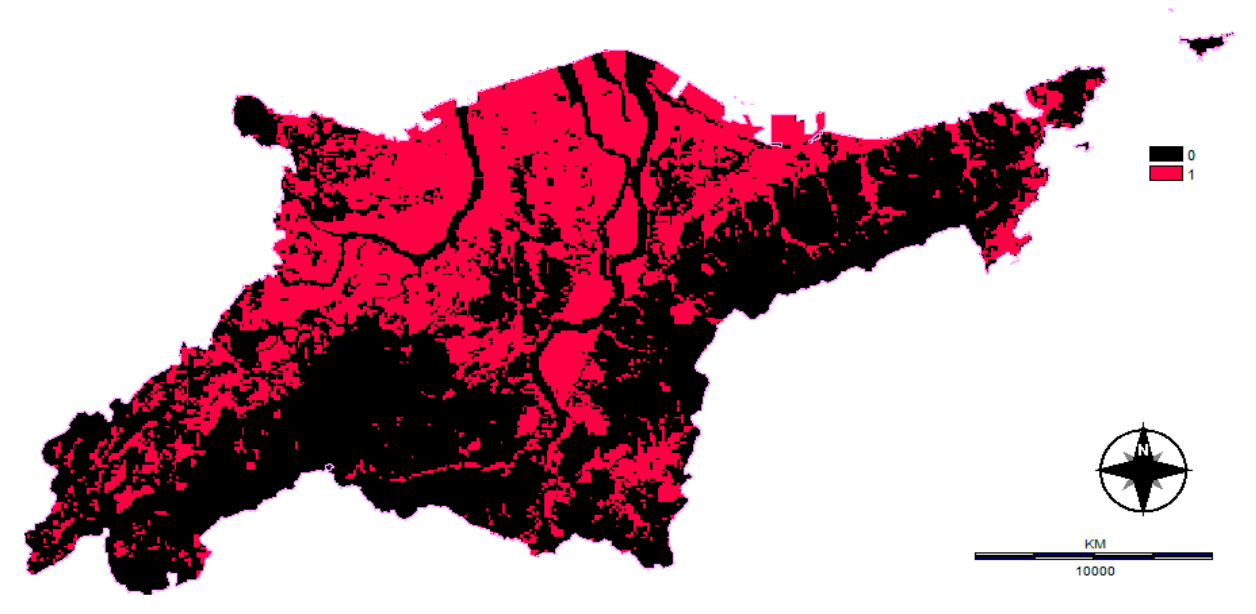

Figure 3. Environmental constraint map.

\subsubsection{Sociocultural Constraint Map}

The same procedure used for the environmental constraints is applied but with separate factors or criteria. Residential areas and touristic and cultural centers are the areas not allowed to be developed; these were reclassified as 0 's, while other places were reclassified as 1's (Figure 4).

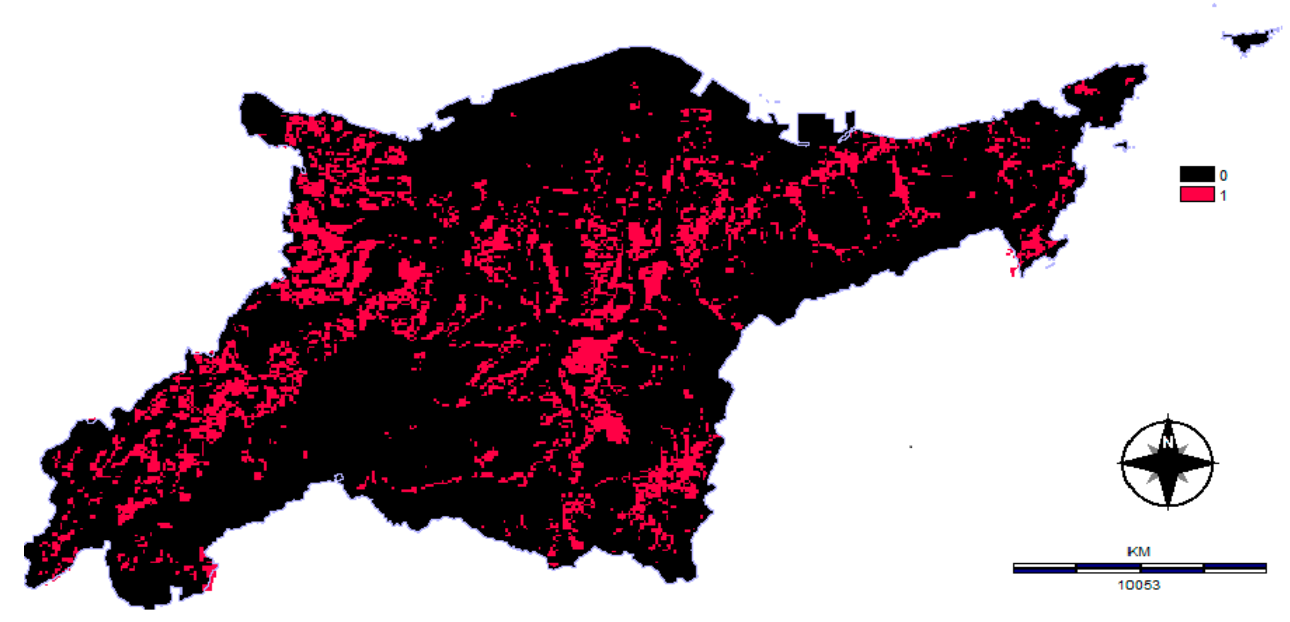

Figure 4. Sociocultural constraint map. 


\subsubsection{Technical/Economic Constraint Map}

For the technical/economic constraints, the slope gradient is considered as a reasonable key factor. Shallow gradients are preferable to developers given that they are cheaper for construction [24]. Furthermore, most literature also identifies the slope gradient as a significant constraint to be considered $[15,16,20,25,30,32]$. The map was obtained using ASTER-DEM data analyzed through a module called SURFACE to produce a slope map in units of degrees. It was then run with a reclass module to produce the technical/economic map with 1 assigned as a new value (acceptable zone) to values in the range (0-20) and 0 assigned to values in the range (21-999) (non-development zone) (Figure 5).

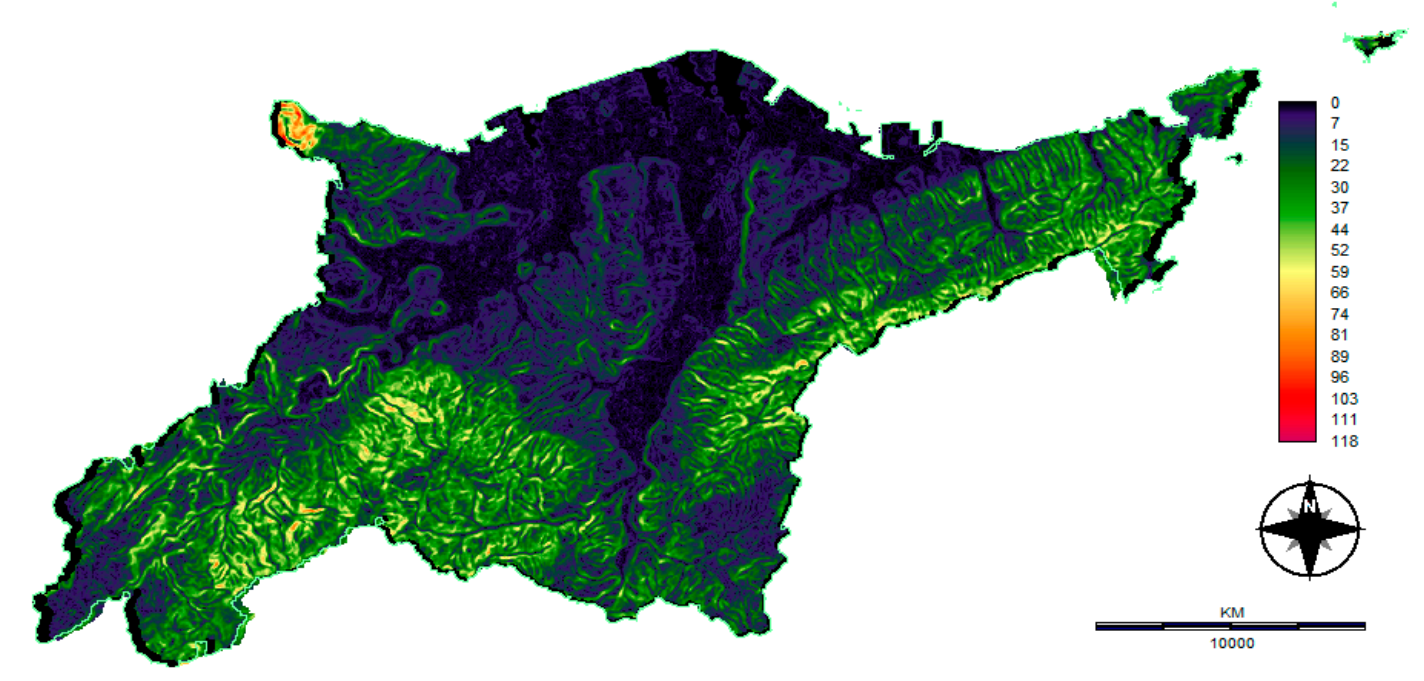

Figure 5. Technical/economical constraint map.

\subsection{Factor Standardization Using Fuzzy Function}

A comprehensive result of standardized factors is given below and is shown in Figure 6. The standardized maps are classified in the range of bytes (from 0 to 255), representing different fuzzy membership decision sets (Figure 6 and Table 2). In this analysis, the suitable fuzzy functions and related control points shown in Table 2 were selected on the basis of a review of the literature in conformity with WMPCL and Oita Prefecture legislation [6,14,15,19-21,23-34,41-44].

Table 2. Standardized factors: membership function and fuzzy set membership with control points used.

\begin{tabular}{|c|c|c|c|}
\hline Constraints and Factors & $\begin{array}{l}\text { Control Points } \\
\text { (a and c) }\end{array}$ & $\begin{array}{l}\text { Control Points } \\
(b \text { and } d)\end{array}$ & Fuzzy Membership Function \\
\hline $\begin{array}{l}\text { Environmental } \\
\sqrt{ } \text { Water bodies } \\
\sqrt{ } \text { Forests }\end{array}$ & $\begin{array}{l}\text { a: } 200 \mathrm{~m} \\
\text { a: } 500 \mathrm{~m}\end{array}$ & $\begin{array}{l}\mathrm{b}: 1000 \mathrm{~m} \\
\mathrm{~b}: 1200 \mathrm{~m}\end{array}$ & $\begin{array}{l}\text { Sigmoidal monotonically increasing } \\
\text { Sigmoidal monotonically increasing }\end{array}$ \\
\hline $\begin{array}{l}\text { Socialcultural } \\
\sqrt{ } \text { Residential areas } \\
\sqrt{ } \text { Touristic and cultural centers }\end{array}$ & $\begin{array}{l}\text { c: } 800 \mathrm{~m} \\
\text { a: } 250 \mathrm{~m}\end{array}$ & $\begin{array}{l}\mathrm{d}: 1500 \mathrm{~m} \\
\mathrm{~b}: 1200 \mathrm{~m}\end{array}$ & $\begin{array}{l}\text { Sigmoidal monotonically decreasing } \\
\text { Sigmoidal monotonically increasing }\end{array}$ \\
\hline $\begin{array}{l}\text { Technical/Economic } \\
\sqrt{ } \text { Roads } \\
\sqrt{ } \text { Slope gradients } \\
\sqrt{ } \text { Powerlines }\end{array}$ & $\begin{array}{l}\text { c: } 100 \mathrm{~m} \\
\text { c: } 10 \% \\
\text { c: } 100 \mathrm{~m}\end{array}$ & $\begin{array}{l}\mathrm{d}: 1000 \mathrm{~m} \\
\mathrm{~d}: 20 \% \\
\mathrm{~d}: 1000 \mathrm{~m}\end{array}$ & $\begin{array}{l}\text { Linear monotonically decreasing } \\
\text { Sigmoidal monotonically decreasing } \\
\text { Linear monotonically decreasing }\end{array}$ \\
\hline
\end{tabular}



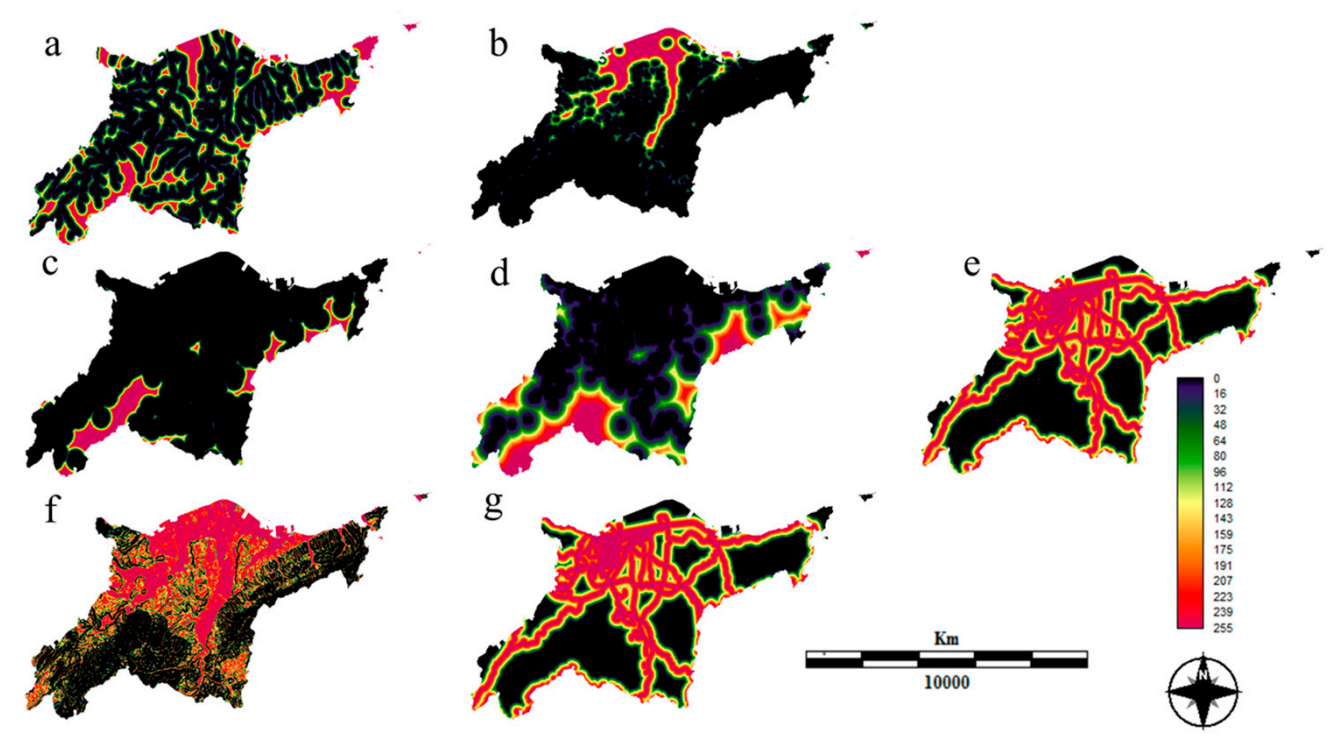

Figure 6. Weighted linear combination (WLC) standardized maps for all seven factors: (a) proximity to water bodies; (b) proximity to forests; (c) proximity to residential areas; (d) proximity to touristic and cultural centers; (e) proximity to roads; (f) proximity to slope gradients; (g) proximity to powerlines.

\subsubsection{Proximity to Water Bodies}

Water bodies in our study denote streams, rivers, and other surface water sources. Water pollution from $\mathrm{AD}$ plants is one of the main environmental concerns, and it is very important to keep to the standards, regulations, and practices of Oita City. Rivers and water mesh data from NLNI and OpenStreetMap (https:/ / www.openstreetmap.org) were used to generate a buffer zone around all forms of water bodies. Then, a sigmoidal monotonically increasing fuzzy membership function was used to standardize the water bodies' factor map with control points a $(200 \mathrm{~m})$ and b $(1000 \mathrm{~m})$, indicating that a distance of $200 \mathrm{~m}$ is the least suitable location, while distances of $1000 \mathrm{~m}$ and beyond are the most suitable locations.

\subsubsection{Proximity to Forests}

Generally, in Japan (including Oita City), forest areas are considered as both ecological and sacred places; therefore, deterioration of these areas may cause communities to oppose the siting of AD plants. This is the second factor considered for the environmental constraints. The distance from forest areas was calculated using the Boolean image extracted from the land-cover map before it was standardized by using the sigmoidal monotonically increasing fuzzy membership function with control points of a $(500 \mathrm{~m})$ and $\mathrm{b}(1200 \mathrm{~m})$. A distance of $1200 \mathrm{~m}$ and more is the most suitable, with the values ranging by up to 255 , while less than $500 \mathrm{~m}$ is not suitable, with the values ranging from 0.

\subsubsection{Proximity to Residential Areas}

The ecological advantage of AD plants over other waste treatment facilities has made it more favorable for them to be sited closer to the source of waste generation. It is still appropriate to site such plants away from residential areas in order to avoid any unforeseen circumstances. Closeness to the source of waste generation will not only reduce the costs of transportation but will also provide a means for the sale of by-products. The cost of transportation and the population density are not direct priorities but indirect priorities, considered under the proximity to residential areas and roads. The image created from the land-cover map, that is, the Boolean image with only the residential areas, was rescaled to a range of suitability. The highest distance has the lowest suitability value of 0 , and the lowest distance was assigned with the highest suitability value of 255 . The sigmoidal 
monotonically decreasing membership function was used with the first control point (c) of $1000 \mathrm{~m}$ and the second control point (d) of $1200 \mathrm{~m}$, signifying that an increase in the distance from residential areas reduces suitability.

\subsubsection{Proximity to Touristic and Cultural Centers}

Areas in which cultural sites, national parks, protected areas, and touristic areas exist are considered not suitable for siting any waste treatment facilities, according to Japanese legislation [38]. This is because there is a high possibility of the local community opposing the siting of an AD plant, as it may have negative impacts on the development of the local tourism industry. The sigmoidal monotonically increasing function was used to rescale the value in the image created from the land-use/cover map with the control points of a $(250 \mathrm{~m})$ and b $(1200 \mathrm{~m})$, signifying that at $250 \mathrm{~m}$, the suitability starts to rise sharply above 0 and that at $1200 \mathrm{~m}$, it starts to level off, reaching the maximum of the scale, 255.

\subsubsection{Proximity to Slope Gradients}

Slope is an important feature in the construction and operation of any waste treatment facility. In the image in Figure 5, the rate of change of height was measured and is expressed as a percentage in the path of the steepest descent. Slopes between 10\% and $20 \%$ are the most beneficial for siting an AD plant. However, areas with the lowest slope are the most suitable, and any slope of more than $20 \%$ is not suitable. The sigmoidal monotonically decreasing fuzzy function was used to standardize the image to the scale of 0 to 255 with the two control points c (10\%) and d (20\%), for which slopes of less than $10 \%$ are the most suitable and slopes above $20 \%$ are equally unsuitable.

\subsubsection{Proximity to Roads}

Proximity to roads refers to major and minor roads, highways, streets, railways, and others. The proximity to road factors image was standardized using control points at $\mathrm{c}(100 \mathrm{~m})$ and $\mathrm{d}$ $(1000 \mathrm{~m})$ with the linear and monotonically decreasing fuzzy membership functions. Therefore, as land suitability increases from 0 to 255 , the distance from roads increases from 100 to $1000 \mathrm{~m}$. The areas considered unsuitable are situated further than $1000 \mathrm{~m}$ from roads.

\subsubsection{Proximity to Powerlines}

Physical distances were used to calculate factor images for the distances from powerlines and roads. Because of the lack of data for electrical powerlines, Eastman's [24] approach to deduce the powerlines from the road image was adopted to obtain the powerline image. The procedure is to reclass the road image, as it is rational to assume that powerlines tend to be associated with paved (bitumen) roads [24]. Afterwards, the same control points and procedures used for the proximity to roads were used to obtain the final standardized suitable image. Figure 6 demonstrates the standardized outcome of all seven factors, and Table 2 indicates the standardized control point used in the fuzzy functions.

\subsection{Pairwise Comparison and WCL Technique}

The set of factor weights shown in Table 3 were calculated using a pairwise comparison method. These factors of relative importance were examined in pairs, in order to achieve the identified goal. The pairwise comparisons of all related factors were utilized to ascertain the relative importance of the factor weights. It should be mentioned that the examined factor weights used in the analysis were based on the collective appraisal of information on the MSW management regulation policy (WMPCL) that mainly represents the FBW situation in Japan and relevant literature on waste disposal/treatment site selection $[3,6,13,15,19,20,26,29,41-43,45,47]$. For instance, the proximity to water bodies is moderately more important than proximity to powerlines in deciding a suitable location for siting an AD plant. Here, the rating of the relative importance of proximity to water bodies to proximity to powerlines 
was $1 / 3$, while the rating of the relative importance of proximity to powerlines to proximity to water bodies was 3 . Therefore, the consistency ratio (CR) fully satisfied the allowed level of inconsistency stated by Saaty [45], as CR ratings of less than 0.10 are acceptable $(0.09<0.10)$.

Table 3. Pairwise comparison matrix for evaluating the comparative importance of seven factors.

\begin{tabular}{|c|c|c|c|c|c|c|c|c|}
\hline & Residential & Slope & Power & Road & Tourist Center & Water & Forest & Priority Vector \\
\hline Residential & 1 & & & & & & & 0.0793 \\
\hline Slope & 3 & 1 & & & & & & 0.3482 \\
\hline Power & 1 & $1 / 3$ & 1 & & & & & 0.1216 \\
\hline Road & 3 & $1 / 3$ & 4 & 1 & & & & 0.2653 \\
\hline Tourist Center & 2 & $1 / 4$ & $1 / 3$ & $1 / 4$ & 1 & & & 0.084 \\
\hline Water & $1 / 3$ & $1 / 6$ & $1 / 3$ & $1 / 6$ & 1 & 1 & & 0.0459 \\
\hline Forest & 2 & $1 / 6$ & $1 / 3$ & $1 / 6$ & 3 & 1 & 1 & 0.0557 \\
\hline
\end{tabular}

Consistency ratio of 0.09 acceptable as it is $<0.1(<10 \%)$.

In aggregating the final image, WCL plays an important part, as it allows for full tradeoff among factors and criteria, such that a factor with strong suitability can offset for other factors with weak suitability, provided that the decision for this compensation is made according to the tradeoff weight that is, factor weight $[24,42]$. The recommended suitable areas for siting an AD plant using all the constraint and factor maps are illustrated in Figure 7.

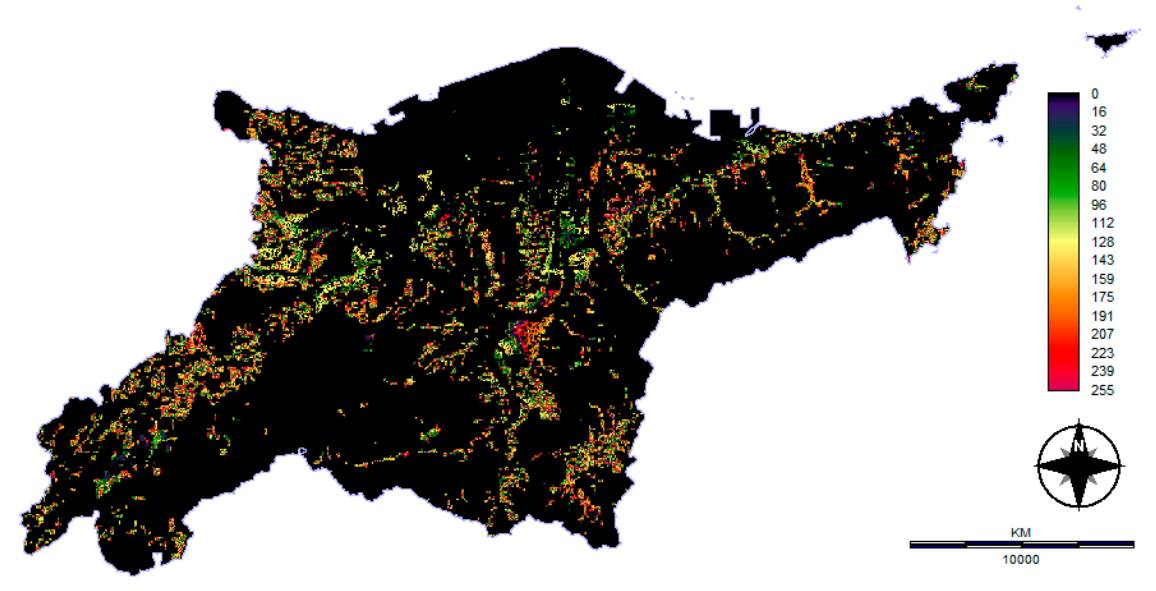

Figure 7. Suitability map layer.

The suitability map layer was categorized using CA, and the suitability of the four clusters was identified: unsuitable, suitable, moderately suitable, and highly suitable. These suitability options are shown in Figure 8. CA is described as being among the unsupervised classification techniques in GIS environments and reads similarities between units and essential groups of applied units, putting all calculated variables simultaneously into consideration [20,24]. Spatial autocorrelation analysis (Moran's I) is a key technique used to evaluate the correction and concentration of spatial autocorrelation maps and cluster, randomization, dispersion, and dependency tests $[15,20]$. Its application in this study showed the robustness of the final suitability result. Spatial autocorrelation (Moran's I) results of a suitable map layer are given in two cases (King's and Rook's cases). The suitable map layer indicated high spatial clustering in both the King's and Rook's cases, with indexes of 0.6265 and 0.6550 , respectively. However, according to the global Moran's I, a suitable map layer of spatial autocorrelation is a well-recognized indicator of the spatial autocorrelation of Moran's I [15,20].

The AHP approach was used to select the most suitable site, resulting in the third suitable option (highly suitable) being the best option. In addition, the WLC calculated mean scores also confirmed this result (Table 4), demonstrating that the priority vectors and judgments appeared to be rational 
and robust, as consistency is accepted with a ratio of 0.09 [19,20,24,45,47]. In Figure 9, a four-level hierarchical structure was used to develop the AHP model. The first level stands for the hierarchy decision goal, the constraints (criteria) are presented in the second level, the third level illustrates the factors (sub-criteria) employed, and the options of suitable areas acquired through WLC and CA are represented in the fourth level.

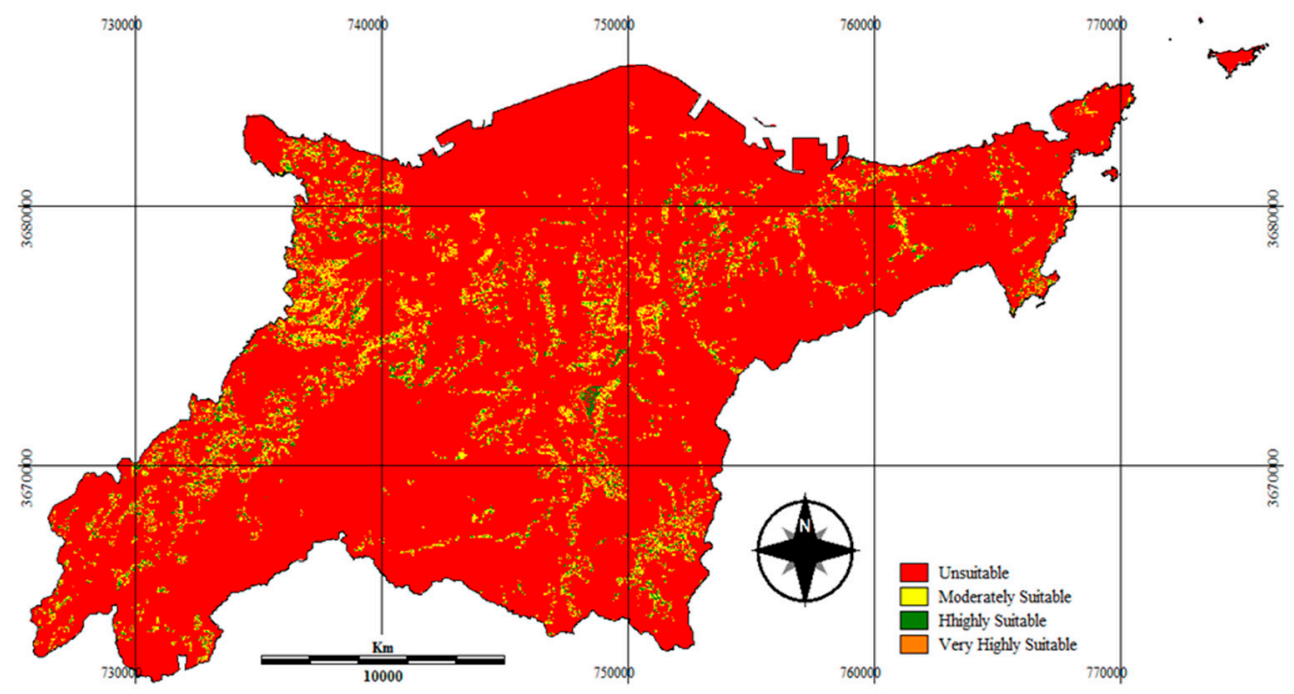

Figure 8. Suitable areas for siting the anaerobic digestion plant.

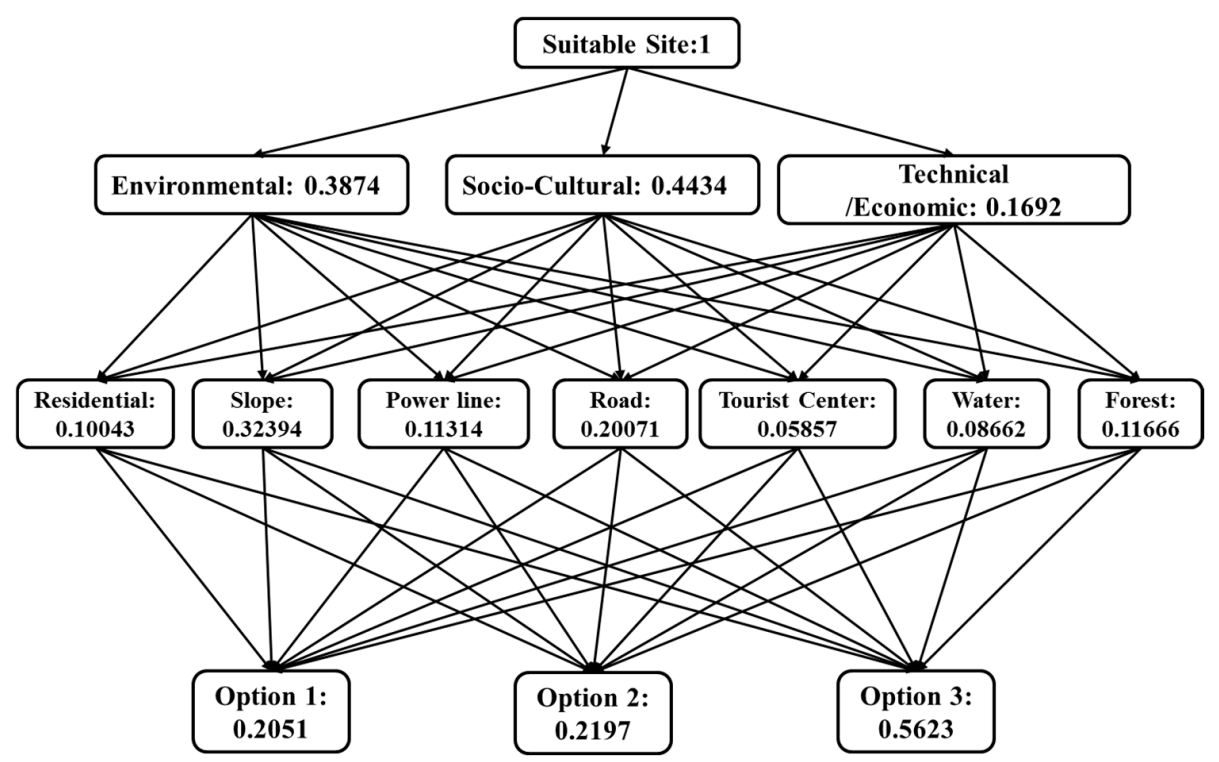

Figure 9. Hierarchy structure of the model used in selecting the most suitable location.

Table 4. Ranking result on the basis of the weighted linear combination (WLC) and analytic hierarchical process (AHP) methods.

\begin{tabular}{lccccccc}
\hline Alternatives & $\begin{array}{c}\text { Minimum } \\
\text { Suitability }\end{array}$ & $\begin{array}{c}\text { Maximum } \\
\text { Suitability }\end{array}$ & Area $\left.\mathbf{( k m}^{\mathbf{2}}\right)$ & $\begin{array}{c}\text { WLC Mean } \\
\text { Score }\end{array}$ & $\begin{array}{c}\text { WLC } \\
\text { Rank }\end{array}$ & $\begin{array}{c}\text { AHP Priority } \\
\text { Weight }\end{array}$ & AHP Rank \\
\hline Option 1 & 94 & 187 & 6731.02 & 136.35 & 3 & 0.2051 & 3 \\
Option 2 & 188 & 233 & 2950.3 & 210.6 & 2 & 0.2197 & 2 \\
Option 3 & 234 & 255 & 1335.79 & 244.75 & 1 & 0.5623 & 1 \\
\hline
\end{tabular}




\section{Discussion}

The use of GIS-MCDA has arisen in decision-making processes as an important tool in waste management for site evaluation, route construction, site selection, and resource allocation and in making prioritized alternative decisions across policies, sectors, or time periods [19,48]. In this study, WLC was the GIS-MCDA tool employed to analyze and evaluate the suitability of locating a site for an AD plant in Oita City. The AHP hierarchy incorporates a large number of pairwise comparisons between criteria (constraints), sub-criteria (factors), and site alternatives into a reliable set of scale scores to assist in making the final choice. The hierarchy structure in this study included one goal, three constraints (environmental, sociocultural, and technical/economic criteria), seven factors (water bodies, forested areas, residential areas, touristic and cultural centers, roads, slope gradients, and powerlines), and three suitable options (suitable, moderately suitable, and highly suitable) organized into three levels in general.

The WLC technique was used because of the advantage of the tradeoffs it allows between multiple criteria and the final value judgement of the alternatives. As seen in Figure 7, the increased index suitability indicated increased site suitability, that is, sites with suitability indicators tending towards zero were usually considered as unsuitable. Sites with indicators increasing towards 255 were estimated to be the best sites for siting our waste treatment facility (AD plant). The results obtained from the clustering procedure are motivating, and they signify that with the method employed, we were capable of obtaining three suitable areas for the siting of an $\mathrm{AD}$ plant; they also give a preliminary ranking of the suitable areas (Table 4). The WLC approach illustrated in this study expresses the successfulness and usefulness of the technique in siting a location for AD. It also presents a significant insight into the relative importance of waste management and strategic objectives of FBWM in Oita City, Japan. This study has provided information in this regard by revealing how this approach in GIS-MCDA can be used to tackle FBWM difficulties.

Through the CA analysis, three suitable site options were produced, and to determine the most suitable site, the AHP ranking method was used. The third suitable option (highly suitable) was acknowledged as the most ideal site for an AD plant. Therefore, a spread of about $13.36 \mathrm{~km}^{2}$ from the entire case study area was most suitable. The remaining two options, suitable $\left(67.31 \mathrm{~km}^{2}\right)$ and moderately suitable $\left(29.50 \mathrm{~km}^{2}\right)$, were still suitable to be used for the intended purpose, but the true decision will have to be entrusted to the decision-makers' judgment. Spatial autocorrelation (Moran's I) was used to evaluate the robustness of the final suitability result, therefore indicating a high spatial clustering in both King's (0.6265) and Rook's cases (0.6550).

It is important to note that the criteria, factors, fuzzy functions (with related control points), and weights used in the analysis were based on the collective appraisal of information on the WMPCL regulation and other related policies that mainly represent site selection of solid waste treatment facilities in Oita City and Japan in general [41]. Decision-making based on a different set of value judgments (weights) would generate different results because of a different set of criteria or factors $[7,29,45]$. Therefore, the GIS-MCDA model proposed in this study can be an adaptive and robust framework that could be customized to fit to a variety of constraints (criteria) or more levels of factors (sub-criteria). The implementation of OWA could also be carried out to check for consistency of the results. It can also act as a guiding framework for the ongoing discussion on site selection for locating any FBW treatment plants or can be used as a benchmark towards realizing and providing suitable sites for AD plant operations.

When planning to implement site selection for MSW management disposal and treatment facilities such as an AD plant, it is essential to take into consideration the series of challenges planners will have to go through, some of which may involve local and municipal authorities, waste management practitioners, environmentalists, and the local communities (citizens). In reality, site-allocation processes are complicated and require numerous elaborated criteria; there are plenty of interactions and relationships that exist between mixtures of criteria. Consequently, the proposed framework can play a vital role not only as a final way of selecting the most suitable site, but also as an instrument with 
the ability and information to facilitate the decision-making process in terms of defining, informing, and guiding. Similarly, it provides room for participation, training, and involvement of representatives from all sectors of Oita City.

\section{Conclusions}

This study demonstrates a GIS-MCDA-based analytical approach for determining and assessing a potentially suitable site for locating an AD plant (waste treatment facility) in Oita City, Japan. The proposals for the siting of the AD, as a treatment option for FBW in Oita City, depend, to some degree, on the assessment of criteria (constraints and factors) and the impacts of various relative weights. The evaluation criteria utilized in this study followed the land and landscape laws of Oita Prefecture, the WMPCL, and relevant literature.

In the WLC analysis, only a few factors (seven) were considered in the sub-criteria, and three criteria were set as constraints. The potential areas for locating an AD plant site were evaluated and examined using the AHP, Fuzzy functions and WLC methods. The results showed that the maximum suitability index is 255 and the minimum suitability index is 94 , indicating that any point below 94 is not suitable for development.

The AHP approach was also used to evaluate the factors by pairwise comparison to generate the global weights, which, by combining with a CA procedure to create and rank, resulted in three suitable options: the first suitable option had a mean score of $136.35\left(67.31 \mathrm{~km}^{2}\right)$, the second moderately suitable option had a mean score of $210.6\left(29.50 \mathrm{~km}^{2}\right)$, and the third highly suitable option ranked as the most suitable with the mean score of $244.75\left(13.36 \mathrm{~km}^{2}\right)$. Hence, this result showed an important layout, outline, and strategy to assist the decision-maker in resolving the challenges connected with the location of FBW treatment facilities.

In general, the framework presented in this study can be used as a well-organized strategic decision supporting tool design to offer and aid local authorities, waste management practitioners, decision-makers, politicians, communities (local citizens), and planners with essential and consistent (goals and objective) information on the evaluation procedure of site selection for FBW treatment. Improvements to the proposed GIS-MCDA model through taking into consideration more constraints and factors and their interactions with regard to their tradeoffs would help to extend the applicability of the model in solving some of the challenges faced by municipal governments.

Funding: No Funding from any organization or individual.

Conflicts of Interest: The author declares no conflict of interest.

\section{References}

1. Takata, M.; Fukushima, K.; Kino-Kimata, N.; Nagao, N.; Niwa, C.; Toda, T. The effects of recycling loops in food waste management in Japan: Based on the environmental and economic evaluation of food recycling. Sci. Total Environ. 2012, 432, 309-317. [CrossRef] [PubMed]

2. Wong, L.-F.; Fujita, T.; Xu, K. Evaluation of regional bioenergy recovery by local methane fermentation thermal recycling systems. Waste Manag. 2008, 28, 2259-2270. [CrossRef] [PubMed]

3. Okuda, I.; Thomson, V.E. Regionalization of municipal solid waste management in Japan: Balancing the proximity principle with economic efficiency. Environ. Manag. 2007, 40, 12-19. [CrossRef] [PubMed]

4. Braber, K. Anaerobic digestion of municipal solid waste: A modern waste disposal option on the verge of breakthrough. Biomass Bioenergy 1995, 9, 365-376. [CrossRef]

5. Sakai, S.; Sawell, S.E.; Chandler, A.J.; Eighmy, T.T.; Kosson, D.S.; Vehlow, J.; Van der Sloot, H.A.; Hartlen, J.; Hjelmar, O. World trends in municipal solid waste management. Waste Manag. 1996, 16, 341-350. [CrossRef]

6. Tavares, G.; Zsigraiová, Z.; Semiao, V. Multi-criteria GIS-based siting of an incineration plant for municipal solid waste. Waste Manag. 2011, 31, 1960-1972. [CrossRef] [PubMed]

7. Babalola, M.A. A multi-criteria decision analysis of waste treatment options for food and biodegradable waste management in Japan. Environments 2015, 2, 471-488. [CrossRef] 
8. Khalid, A.; Arshad, M.; Anjum, M.; Mahmood, T.; Dawson, L. The anaerobic digestion of solid organic waste. Waste Manag. 2011, 31, 1737-1744. [CrossRef] [PubMed]

9. ISWA-The International Solid Waste Association. Food Waste as a Global Issue-From the Perspective of Municipal Solid Waste Management; Key Issue Paper; ISWA Publications: Vienna, Austria, 2013.

10. Khoo, H.H.; Lim, T.Z.; Tan, R.B.H. Food waste conversion options in Singapore: Environmental impacts based on an LCA perspective. Sci. Total Environ. 2010, 408, 1367-1373. [CrossRef] [PubMed]

11. Franchetti, M. Economic and environmental analysis of four different configurations of anaerobic digestion for food waste to energy conversion using LCA for: A food service provider case study. J. Environ. Manag. 2013, 123, 42-48. [CrossRef] [PubMed]

12. Mata-Alvarez, J.; Mace, S.; Llabres, P. Anaerobic digestion of organic solid wastes. An overview of research achievements and perspectives. Bioresour. Technol. 2000, 74, 3-16. [CrossRef]

13. Kemal Korucu, M.; Erdagi, B. A criticism of applications with multi-criteria decision analysis that are used for the site selection for the disposal of municipal solid wastes. Waste Manag. 2012, 32, 2315-2323. [CrossRef] [PubMed]

14. Gbanie, S.P.; Tengbe, P.B.; Momoh, J.S.; Medo, J.; Kabba, V.T.S. Modelling landfill location using Geographic Information Systems (GIS) and Multi-Criteria Decision Analysis (MCDA): Case study Bo, Southern Sierra Leone. Appl. Geogr. 2013, 36, 3-12. [CrossRef]

15. Kontos, T.D.; Komilis, D.P.; Halvadakis, C.P. Siting MSW landfills with a spatial multiple criteria analysis methodology. Waste Manag. 2005, 25, 818-832. [CrossRef] [PubMed]

16. OzeairAbessi, M.S. Site Selection of a Hazardous Waste Landfill Using GIS Technique and Priority Processing, a Power Plant Waste in Qazvin Province Case Example. Environ. Sci. 2009, 6, 121-134.

17. Khan, S.; Faisal, M.N. An analytic network process model for municipal solid waste disposal options. Waste Manag. 2008, 28, 1500-1508. [CrossRef] [PubMed]

18. Malczewski, J. Spatial Multicriteria Decision Analysis. In Spatial Multicriteria Decision Making and Analysis: A Geographic Information Sciences Approach; Jean-Claude, T., Ed.; Ashgate Publishing Ltd.: London, UK, 1999; pp. 11-48.

19. Malczewski, J. GIS-based multicriteria decision analysis: A survey of the literature. Int. J. Geogr. Inf. Sci. 2006, 20, 703-726. [CrossRef]

20. Moeinaddini, M.; Khorasani, N.; Danehkar, A.; Darvishsefat, A.A.; Zienalyan, M. Siting MSW landfill using weighted linear combination and analytical hierarchy process (AHP) methodology in GIS environment (case study: Karaj). Waste Manag. 2010, 30, 912-920. [CrossRef] [PubMed]

21. Sharifi, M.; Hadidi, M.; Vessali, E.; Mosstafakhani, P.; Taheri, K.; Shahoie, S.; Khodamoradpour, M. Integrating multi-criteria decision analysis for a GIS-based hazardous waste landfill sitting in Kurdistan Province, Western Iran. Waste Manag. 2009, 29, 2740-2758. [CrossRef] [PubMed]

22. Khalili, N.R.; Duecker, S. Application of multi-criteria decision analysis in design of sustainable environmental management system framework. J. Clean. Prod. 2013, 47, 188-198. [CrossRef]

23. Duarte, L.; Teodoro, A.C.; Maia, D.; Barbosa, D. Radio Astronomy Demonstrator: Assessment of the Appropriate Sites through a GIS Open Source Application. ISPRS Int. J. Geo-Inf. 2016, 5, 209. [CrossRef]

24. Eastman, J.R. IDRISI Taiga-Guide to GIS and Image Processing; Clark Labs., Clark University: Worcester, MA, USA, 2009.

25. Al-Jarrah, O.; Abu-Qdais, H. Municipal solid waste landfill siting using intelligent system. Waste Manag. 2006, 26, 299-306. [CrossRef] [PubMed]

26. Aragonés-Beltrán, P.; Pastor-Ferrando, J.P.; García-García, F.; Pascual-Agulló, A. An Analytic Network Process approach for siting a municipal solid waste plant in the Metropolitan Area of Valencia (Spain). J. Environ. Manag. 2010, 91, 1071-1086. [CrossRef] [PubMed]

27. Chang, N.-B.; Parvathinathan, G.; Breeden, J.B. Combining GIS with fuzzy multicriteria decision-making for landfill siting in a fast-growing urban region. J. Environ Manag. 2008, 87, 139-153. [CrossRef] [PubMed]

28. Ekmekçioğlu, M.; Kaya, T.; Kahraman, C. Fuzzy multicriteria disposal method and site selection for municipal solid waste. Waste Manag. 2010, 30, 1729-1736. [CrossRef] [PubMed]

29. Gorsevski, P.V.; Donevska, K.R.; Mitrovski, C.D.; Frizado, J.P. Integrating multi-criteria evaluation techniques with geographic information systems for landfill site selection: A case study using ordered weighted average. Waste Manag. 2012, 32, 287-296. [CrossRef] [PubMed] 
30. Salman Mahini, A.; Gholamalifard, M. Siting MSW landfills with a weighted linear combination (WLC) methodology in a GIS environment. Int. J. Environ. Sci. Technol. 2006, 3, 435-445. [CrossRef]

31. Sumathi, V.R.; Natesan, U.; Sarkar, C. GIS-based approach for optimized siting of municipal solid waste landfill. Waste Manag. 2008, 28, 2146-2160. [CrossRef] [PubMed]

32. Wang, G.; Qin, L.; Li, G.; Chen, L. Landfill site selection using spatial information technologies and AHP: A case study in Beijing, China. J. Environ. Manag. 2009, 90, 2414-2421. [CrossRef] [PubMed]

33. Chang, N.-B.; Chang, Y.-H.; Chen, H.-W. Fair fund distribution for a municipal incinerator using GIS-based fuzzy analytic hierarchy process. J. Environ. Manag. 2009, 90, 441-454. [CrossRef] [PubMed]

34. Chiueh, P.-T.; Lo, S.-L.; Chang, C.-L. A GIS-based system for allocating municipal solid waste incinerator compensatory fund. Pay as you throw: A tool for urban waste management. Waste Manag. 2008, 28, 2690-2701. [CrossRef] [PubMed]

35. Oita City. Statistics of Oita-City (2017 Version). 2018. Available online: http:/ /www.city.oita.oita.jp.e.adk.hp. transer.com/o001/shisejoho/annai/tokei-nenkan-h29.html (accessed on 22 April 2018).

36. Oita Pride. Oita City Outline 2017. Available online: http://www.city.oita.oita.jp/o029/shisejoho/annai/ documents/english.pdf (accessed on 22 April 2018).

37. Ministry of the Environment (MOE). Establishing a Sound Material-Cycle Society: Milestone toward a Sound Material-Cycle Society through Changes in Business and Life Styles; Ministry of the Environment Government: Tokyo, Japan, 2010. Available online: http://www.env.go.jp/en/recycle/smcs/a-rep/2010gs_full.pdf (accessed on 20 September 2015).

38. Oita Municipal Government. Oita Zero Waste Strategy: The Status and Plans of Biomass Resource Utilization; Oita Municipal Government: Oita City, Japan, 2014.

39. ASTER Global Digital Elevation Model (ASTER GDEM) Version 2 (3 October 2011). Available online: https:/ / ssl.jspacesystems.or.jp/ersdac/GDEM/E/4.html (accessed on 15 June 2015).

40. National Land Numerical Information Version 3.1. City Area Data. Available online: http://nlftp.mlit.go.jp/ ksj-e/gml/datalist/KsjTmplt-A09.html (accessed on 15 June 2015).

41. Ordinance No. 35 of Ministry of Health and Welfare of 1971. Regulations of Waste Management and Public Cleansing Law; Ministry of the Environment: Tokyo, Japan, 2002. Available online: https:/ /www.env.go.jp/ en/laws/recycle/03.pdf (accessed on 20 September 2015).

42. Demesouka, O.E.; Vavatsikos, A.P.; Anagnostopoulos, K.P. Suitability analysis for siting MSW landfills and its multicriteria spatial decision support system: Method, implementation and case study. Waste Manag. 2013, 33, 1190-1206. [CrossRef] [PubMed]

43. Şener, Ş.; Şener, E.; Nas, B.; Karagüzel, R. Combining AHP with GIS for landfill site selection: A case study in the Lake Beyşehir catchment area (Konya, Turkey). Waste Manag. 2010, 30, 2037-2046. [CrossRef] [PubMed]

44. Drobne, S.; Lisec, A. Multi-attribute Decision Analysis in GIS: Weighted Linear Combination and Ordered Weighted Averaging. Informatica 2009, 33, 459.

45. Saaty, T.L. The Analytic Hierarchy Process: Planning, Priority Setting, Resource Allocation; McGraw-Hill International Book Co.: New York, NY, USA, 1980.

46. Saaty, T.L.; Vargas, L.G. Models, Methods, Concepts \& Applications of the Analytic Hierarchy Process; Kluwer Academic Publishers: Boston, MA, USA, 2001.

47. Saaty, T.L.; Sagir, M. An essay on rank preservation and reversal. Math. Comput. Model. 2009, 49, 1230-1243. [CrossRef]

48. Malczewski, J. On the Use of Weighted Linear Combination Method in GIS: Common and Best Practice Approaches. Trans. GIS 2000, 4, 5-22. [CrossRef]

(C) 2018 by the author. Licensee MDPI, Basel, Switzerland. This article is an open access article distributed under the terms and conditions of the Creative Commons Attribution (CC BY) license (http://creativecommons.org/licenses/by/4.0/). 